\title{
Draft Sequencing and Comparative Genomics of Xylella fastidiosa Strains Reveal Novel Biological Insights
}

\author{
Anamitra Bhattacharyya, ${ }^{1,8}$ Stephanie Stilwagen, ${ }^{2}$ Gary Reznik, ${ }^{1}$ Helene Feil, ${ }^{3}$ \\ William S. Feil, ${ }^{4}$ lain Anderson, ${ }^{1}$ Axel Bernal, ${ }^{1}$ Mark D'Souza, ${ }^{1}$ Natalia Ivanova, ${ }^{1}$ \\ Vinayak Kapatral, ${ }^{1}$ Niels Larsen, ${ }^{1}$ Tamara Los, ${ }^{1}$ Athanasios Lykidis, ${ }^{1}$ \\ Eugene Selkov Jr., ${ }^{1}$ Theresa L. Walunas, ${ }^{1}$ Alexander Purcell, ${ }^{4}$ Rob A. Edwards, ${ }^{5}$ \\ Trevor Hawkins, ${ }^{2}$ Robert Haselkorn, ${ }^{6}$ Ross Overbeek, ${ }^{1}$ Nikos C. Kyrpides, ${ }^{1}$ and \\ Paul F. Predki ${ }^{2,7}$ \\ ${ }^{1}$ Integrated Genomics, Inc., Chicago, Illinois 60612, USA; ${ }^{2}$ Department of Energy, Joint Genome Institute, Walnut Creek, \\ California 94598, USA; ${ }^{3}$ Department of Plant and Microbial Biology, University of California, Berkeley, California 94720, \\ USA; ${ }^{4}$ Department of Environmental Science, Policy, and Management, University of California, Berkeley, California 94720 , \\ USA; ${ }^{5}$ Department of Microbiology, University of Tennessee, Memphis, Tennessee 38163, USA; SUP6Departments of \\ Molecular Genetics \& Cell Biology and Biochemistry \& Molecular Biology, Chicago, Illinois 60637, USA; ${ }^{7}$ Protometrix, Inc., \\ Guilford, Connecticut 06437, USA
}

\begin{abstract}
Draft sequencing is a rapid and efficient method for determining the near-complete sequence of microbial genomes. Here we report a comparative analysis of one complete and two draft genome sequences of the phytopathogenic bacterium, Xylella fastidiosa, which causes serious disease in plants, including citrus, almond, and oleander. We present highlights of an in silico analysis based on a comparison of reconstructions of core biological subsystems. Cellular pathway reconstructions have been used to identify a small number of genes, which are likely to reside within the draft genomes but are not captured in the draft assembly. These represented only a small fraction of all genes and were predominantly large and small ribosomal subunit protein components. By using this approach, some of the inherent limitations of draft sequence can be significantly reduced. Despite the incomplete nature of the draft genomes, it is possible to identify several phage-related genes, which appear to be absent from the draft genomes and not the result of insufficient sequence sampling. This region may therefore identify potential host-specific functions. Based on this first functional reconstruction of a phytopathogenic microbe, we spotlight an unusual respiration machinery as a potential target for biological control. We also predicted and developed a new defined growth medium for Xylella.
\end{abstract}

[The sequence data from this study have been submitted to GenBank under accession nos. NC_002723 (X. fastidiosa Almond [Dixon]) and NC_002722 (X. fastidiosa Oleander [Ann-1]).

\begin{abstract}
Xylella fastidiosa is a Gram-negative bacterium belonging to the gamma subgroup of the proteobacteria (Wells et al. 1987). This microorganism is an important plant pathogen causing many economically important crop diseases, such as Pierce's disease (PD) of grapevine and citrus variegated chlorosis in citrus (Moller et al. 1974; Purcell 1997). Almond leaf scorch was first described in 1974 (Moller et al. 1974), and electron microscope studies indicated the presence in almond of the same bacterium previously associated with PD of grapevines (Mircetich et al. 1976). Cross-inoculation studies showed that $\mathrm{PD}$ and the almond leaf scorch strains were pathogenic to

${ }^{8}$ Corresponding author.

E-MAIL anamitra@integratedgenomics.com; FAX (312) 2269446.

Article and publication are at http://www.genome.org/cgi/doi/10.1101/ gr.370702.
\end{abstract}

both almond and grape (Davis and Thompson 1980). Oleander leaf scorch was first noticed in 1994 in southern California. The glassy-winged sharpshooter, Homalodisca coagulata, was found to be the vector for this bacterium. It is possible that several other varieties of sharpshooters can transmit $X$. fastidiosa between oleander plants (Purcell et al. 1999). The oleander leaf scorch strain could not be reisolated from grapevine in a greenhouse after inoculation using needle puncture (Purcell et al. 1999). This result provides evidence for host specificity among strains of $X$. fastidiosa. Previous studies classified $X$. fastidiosa as a single species, but differentiated members of the species, depending on such criteria as host specificity and pathogenicity (Hendson et al. 2001 and references therein). We define each strain of $X$. fastidiosa to be a pathovar for a specific plant, as suggested previously (Hendson et al. 2001). We will therefore refer throughout to the citrus, al- 
mond, and oleander strains as $X f p v$ citrus (XFA), $X f p v$ almond (XFX), and $X f p v$ oleander (XFY).

The complete genome sequence of the $X$. fastidiosa $9 \mathrm{a} 5 \mathrm{c}$ strain (XFA), which causes citrus variegated chlorosis, was recently published (Simpson et al. 2000). In this study, we report the gapped-genome sequences of $X f p v$ almond (Dixon strain) (XFX) and $X f p v$ oleander (Ann-1 strain) (XFY) and compare them to the complete genomic sequence of XFA. Here we present highlights of the first functional reconstruction of a phytopathogenic microbe based on the three sequenced genomes. This approach has led us to the identification of a putative drug target in the aerobic respiratory chain of this organism, as well as to a prediction of the specific growth requirements of this bacterium, which were used to develop a defined medium for optimal growth. Furthermore, based on a global alignment of the proteomes for these genomes, we identified a region in XFA that is absent in the other two genomes that potentially encodes host-specific functions. Comparisons of curated pathways and their components present in the complete XFA genome relative to the gapped XFY and XFX genomes allows the prediction of functions potentially missed during gapped-genome sequencing. Such an approach provides an added level of quality control to the analysis of sequenced genomes.

\section{RESULTS AND DISCUSSION}

\section{Gapped-Genome Sequencing of New Xf Strains}

The capacity to produce draft genomes based on a random shotgun approach (Fleischmann et al. 1995) far exceeds our capacity to produce completely finished genomes. The draftsequencing process is faster (two to three weeks compared with months or years for finished sequence) and much less expensive. The gapped-genomic sequence of the two new $X y$ lella strains (XFX and XFY) represents more than 95\% of the complete sequence, with 9.4- and 8.1-fold sequence coverage, respectively (Table 1 ). As we hereby show, the microbial draft sequences (high-quality annotated assemblies from $>8$-fold coverage) offers an extremely useful form of information, leading to an effective sampling of $>95 \%$ of the gene repertoire of a given microbial genome. The genome size of both almond (XFX) and oleander (XFY) strains is very similar to the completely sequenced XFA genome, with $2.4 \mathrm{Mb}$ (XFX) and $2.6 \mathrm{Mb}$ (XFY), compared with $2.7 \mathrm{Mb}$ for the XFA genome. All three strains display a similar GC content. We identified 2681 (XFX) and 2870 (XFY) ORFs distributed over 121 and 93 contigs, respectively, compared with the 2985 ORFs of the XFA genome. Using the ERGO bioinformatics suite, we assigned functions to $62 \%$ of the genes in each of the two new Xylella genomes, compared with the $58 \%$ of genes in the XFA genome. Of the remaining $38 \%$ of the ORFs in the XFX and XFY genomes, most show sequence similarity to other proteins of unknown function (hypothetical proteins), and only 3\%-4\% of the total ORFs in the two genomes did not show any sequence similarity to other known proteins (unique ORFs).

Nearly $59 \%$ of the ORFs in any of the three Xylella genomes can be grouped in ortholog clusters and $22 \%$ in para$\log$ clusters. Interestingly, the number of paralog clusters in XFY is less than that in XFA, but there are more ORFs in the XFY paralog clusters compared with the XFA strain. This result indicates that there is greater functional redundancy in the oleander strain, XFY.

\section{Identification of Xf Oleander (XFY) Episome}

The sequencing and assembly of the XFY genome revealed that it possesses a putative $30-\mathrm{kb}$ episome (Table 2). The plasmid bears 36 ORFs, of which three encode proteins involved in replication (RXFY0974, RXFY0979) and plasmid maintenance and stability (RXFY0987). A Type IV secretion pathway (chromosomal cluster) that includes VirB2 (RXFY02430), B4 (RXFY00976), B5 (RXFY00992), B6 (RXFY00989), B8 (RXFY00988), B9 (RXFY00984), B10 (RXFY00977), B11 (RXFY00991), and VirD4 (RXFY00973), as well as a putative transcriptional regulator (RXFY00983) are encoded on the 30$\mathrm{kb}$ replicon. The VirB system is designed to mediate the plasmid transfer from a donor to a recipient bacterium. Two members of the DNA conjugative transfer pathway (TraM, RXFY02499 and TrbN, RXFY00996) have also been found

Table 1. Comparative Statistics of Sequenced Genomes of Xylella fastidiosa Strains

\begin{tabular}{|c|c|c|c|}
\hline & $X f \mathrm{pv}$ citrus $^{\mathrm{a}}$ (XFA) & $X f$ pv oleander (XFY) & $X f \mathrm{pv}$ almond (XFX) \\
\hline Affected plants & Citrus & Oleander & Almond \\
\hline Disease caused & Citrus variegated chlorosis & Oleander leaf scorch & Almond leaf scorch \\
\hline Sequencing source & ONSA & This study & This study \\
\hline DNA, total sequenced bases & $2,731,748$ & $2,625,581$ & $2,434,849$ \\
\hline Contigs & 3 & 93 & 121 \\
\hline Coverage & Complete & $\sim 8.1 \mathrm{X}$ & $\sim 9.4 \mathrm{X}$ \\
\hline $\mathrm{G}+\mathrm{C}$ content & $53 \%$ & $52 \%$ & $52 \%$ \\
\hline Total ORFs & 2985 & 2870 & 2681 \\
\hline Assigned functions & $58 \%$ (1684 ORFs) & $62 \%$ (1713 ORFs) & $62 \%$ (1593 ORFs) \\
\hline \multirow{2}{*}{ Unassigned functions } & $42 \%$ & $38 \%$ & $38 \%$ \\
\hline & $\begin{array}{cc}\text { Unique } & \text { Hypothetical } \\
7 \% & 35 \%\end{array}$ & $\begin{array}{cc}\text { Unique } & \text { Hypothetical } \\
4 \% & 34 \%\end{array}$ & $\begin{array}{cc}\text { Unique } & \text { Hypothetical } \\
3 \% & 35 \%\end{array}$ \\
\hline ORFs in ortholog clusters & $60 \%$ & $58 \%$ & $59 \%$ \\
\hline ORFs in paralog clusters & $21 \%(639)$ & $23 \%(660)$ & $22 \%(585)$ \\
\hline Paralog clusters & 252 & 230 & 220 \\
\hline ORFs in chromosomal clusters & $32 \%$ & $29 \%$ & $26 \%$ \\
\hline
\end{tabular}


Table 2. Comparative Statistics of the $X f$ pv oleander (XFY) and $X f \mathrm{pv}$ citrus (XFA; p51) Eplsomes

\begin{tabular}{lcc}
\hline Plasmid statistics & XFY & XFA $^{\mathbf{a}}$ \\
\hline Length (bp) & 30,270 & 51,158 \\
G+C ratio & $49 \%$ & $49.6 \%$ \\
Protein-encoding regions & $26.9 \%$ & $86.9 \%$ \\
ORFs & 36 & 70 \\
ORFs with functional assignment & $25(69 \%)$ & $34(48 \%)$ \\
Hypothetical proteins & 8 & 31 \\
ORFs without significant database match & 3 & 5 \\
\hline
\end{tabular}

aBased on previously published data (Simpson et al. 2000).

along with a "nickase" (RXFY0985), which is responsible for initiating transposition by introducing single-stranded nicks in the circular plasmid DNA.

\section{Pathway Analysis}

As part of the $X$. fastidiosa functional reconstruction (described later), ORFs were assigned to the appropriate metabolic and nonmetabolic pathways (Kyrpides et al. 2000; Selkov et al. 2000). Figure 1 shows the statistics of functional roles in all three organisms according to subsystem in more detail. Table 3 indicates that a similar number of pathways are present in all three $X f$ strains. Because the citrus (XFA) genome is complete, the percent of functions that appear missing from pathways (Table 3 ) is likely to represent instances of nonorthologous gene replacement, that is, the replacement of a particular protein function by unrelated protein(s) with the
Table 3. Prediction of Functions Missing from Pathways in Gapped XfGenomes

\begin{tabular}{|c|c|c|c|}
\hline & $\begin{array}{c}\text { XFA } \\
\text { (citrus) }\end{array}$ & $\begin{array}{c}\text { XFY } \\
\text { (oleander) }\end{array}$ & $\begin{array}{c}\text { XFX } \\
\text { (almond) }\end{array}$ \\
\hline \multirow{2}{*}{$\begin{array}{l}\text { Pathways asserted } \\
\text { Functional roles } \\
\text { missing from } \\
\text { pathways }\end{array}$} & 958 & 965 & 938 \\
\hline & 352 & 359 & 379 \\
\hline \multicolumn{4}{|c|}{ Examples of functions missing from pathways } \\
\hline Ribosomal SSU & - & 1 & 10 \\
\hline Ribosomal LSU & - & 4 & 17 \\
\hline $\begin{array}{l}\text { Aminoacyl tRNA } \\
\text { synthetases }\end{array}$ & - & 1 & 2 \\
\hline Recombinational & & & \\
\hline repair & - & - & 1 (recF) \\
\hline Replication, elongation & - & - & 1 (DNA Pol III $\beta)$ \\
\hline Total & - & 6 & 31 \\
\hline
\end{tabular}

(LSU) large ribosomal subunit; (SSU) small ribosomal subunit.

same cellular function (Forterre 1999; Galperin and Koonin 1999). Therefore, the number of functions missing from pathways for XFA represents the relative baseline of functions that appear as "absent". Given that ERGO integrates a database of cellular pathways, it is possible to predict which of the functional roles that appear as missing from the XFX/XFY pathways are likely to reside in their nonsequenced regions. We define a functional role as a step in a pathway, and one functional role may have more than one biochemical function.
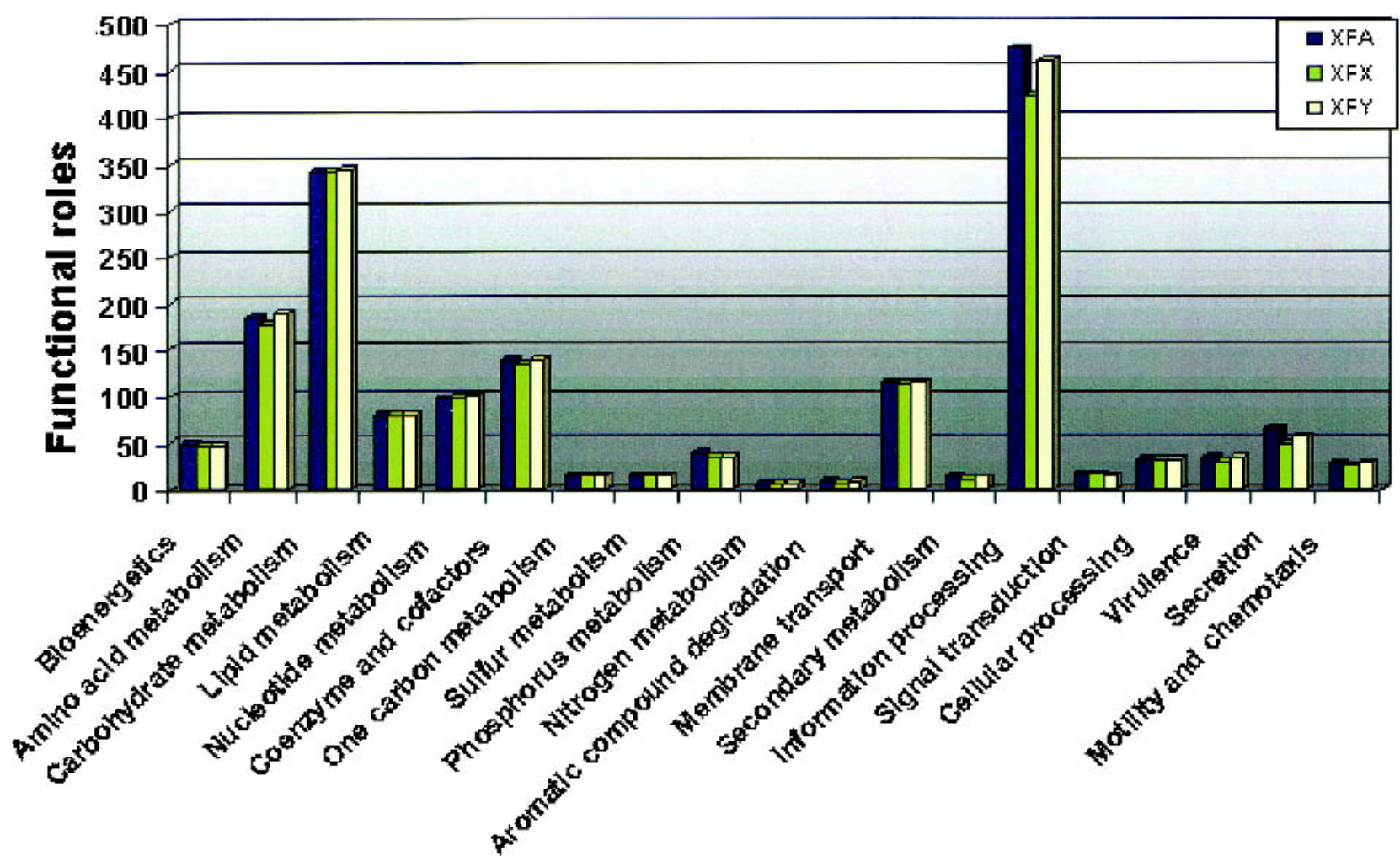

Figure 1 Comparative disposition of functional roles in cellular subsystems in $X f$ genomes. The number of functional roles present in the each of the described subsystems was plotted for each of the Xylella genomes. 
For example, there are 40 and 97 functional roles missing from the genomes of XFY and XFX, respectively, but present in XFA (Table 3). A comparison of these genomes shows a similar number of functional roles associated with each subsystem. Most of the missing functions in almond and oleander strains are present in informational processing pathways (Table 3). Some of these missing functions represent components of the core functional machinery (for example, subunits of the large and small ribosomal complexes), and therefore we would expect them to be present in the nonsequenced gaps. More rigorous investigation of these cases indicated that although these functions are indeed present in these genomes, some are associated with ORFs residing on contigs with $<20$ reads, which have lower coverage and sequence quality (see Methods). We speculate that the functional absences present in the secretion subsystem in XFX (Table 3) are likely due to the fact that a plasmid-borne 'pathogenicity island' was not clearly identified in XFX, in contrast to the XFA and XFY. Thus, the pathway analysis approach introduces an additional quality control step in the reconstruction of a partial genome and allows a greater degree of functionality to be assigned to sequenced genomes.

\section{Phage Integration Region Identifies Potential Host-Specific Functions}

During our comparative analysis of the three Xylella genomes, we noticed that the XFA genome contains two tRNA genes (encoding glycine and threonine, at 1,638,644 and 1,707,587 $\mathrm{bp)}$ that flank a region marked by the presence of prophage genes absent from the XFX and XFY genomes. This region was identified in the XFA genome using a comparative genome/ proteome alignment tool called GenomeWalk, the visual rendering of which is shown in Figure 2. The putative phage encoded in this region is most similar to the Siphophage group of double-stranded DNA phage based on wholegenome level and taxonomic comparisons (Rohwer and Edwards 2002). The DNA sequence in this region has a mean GC content of $65.9 \%$, significantly greater than that found in the XFA genome as a whole (52.6\%), indicating that it has been inherited relatively recently in the evolution of the $X f$ genome. This region also contains genes encoding integrase enzymes and DNA replication machinery, as well as genes encoding structural proteins such as capsid and tail proteins.

Closer inspection of this prophage region reveals that it contains two unusual "operons". These operons are striking by the presence of oxidoreductase, dehydrogenase, esterase, hydrolase, and isomerase enzymes, as well as outer membrane permease/transporter proteins, indicating that they are in- volved in carbon-utilization pathways. Both operons are completed by LysR-family transcriptional regulators that presumably control transcription of the genes in response to environmental signals. It is unclear which carbon-utilization pathways these enzymes are involved in, although the limited distribution (no close orthologs previously identified) indicates that these operons may provide host-specific functions to XFA that are not present in other $X f$ strains. The completeness of the proteins encoded in this region, the lack of similar prophage in related $X f$ genomes, and the similarity between this phage and prophage found in the enteric Salmonella typhi genome recently sequenced (Parkhill 2000) might indicate that this is still a viable phage and not a cryptic remnant of an invading parasite.

\section{Functional Reconstruction}

We embarked on a functional reconstruction of the $X$. fastidiosa $(X f)$ genomes based on the genomic DNA sequences. A more detailed description of how this is done has been published previously (Kyrpides et al. 2000; Selkov et al. 2000; DelVecchio et al. 2002; Kapatral et al. 2002). Here, we present selected highlights of this analysis specifically pertaining to respiratory mechanisms and some of the core metabolism that is relevant to the growth of the bacteria.

Reconstruction of electron transport in Xylella spp. was performed by analyzing the respiratory complexes, both anaerobic and aerobic, as well as proton transport and ATPase. In contrast to previous interpretations (Simpson et al. 2000), the resulting overview indicates that the $X f$ strains possess quite a simple and unusual aerobic respiratory complex (Fig. $3 \mathrm{~A}, \mathrm{~B})$ that does not have the adaptive capabilities of, for instance, Escherichia coli or Bacillus subtilis. Functional analysis in silico shows the presence of the least energy-efficient type of aerobic respiration of any known organism reported to date. The ORF numbering corresponds to the XFA genome, but orthologs in the XFX and XFY strains are present. All three $X f$ possess cytochrome o (bo) ubiquinol oxidase (EC 1.10.3.-) as the only terminal oxidase (RXFA01387-1390). Such a limited system of aerobic respiration indicates that this type of energy metabolism is not a prevalent pathway for this bacterial family. In addition, it indicates that $X f$ are capable of aerobic respiration at high aeration levels but not under oxygenlimiting conditions, because of the absence of cytochromes with high oxygen affinity. Surprisingly, there is no trace of a cytochrome c oxidase (or other type of quinol oxidase as the terminal oxidase) despite the availability of the entire operon encoding the ubiquinol-cytochrome c reductase complex (EC 1.10.2.2; complex III: Rieske iron-sulfur protein, cytochrome

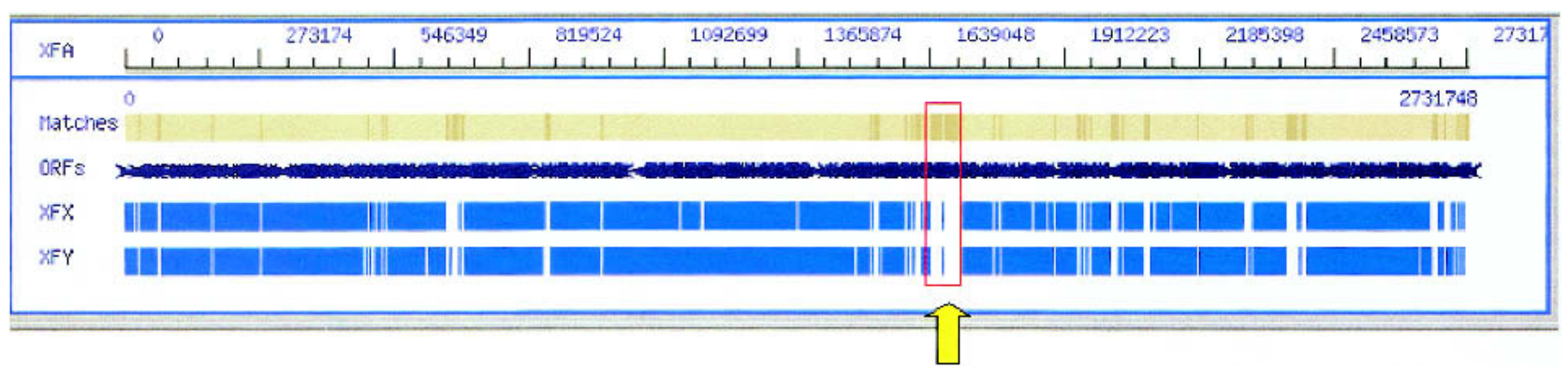

Figure 2 Graphical alignment of Xylella fastidiosa $(X f)$ proteomes using GenomeWalk. A unique 65-kb phage insertion region (red rectangle, brown shading) in the Xf citrus strain (XFA) is absent in the $X f$ almond (XFX) and oleander (XFY) strains (arrow). 


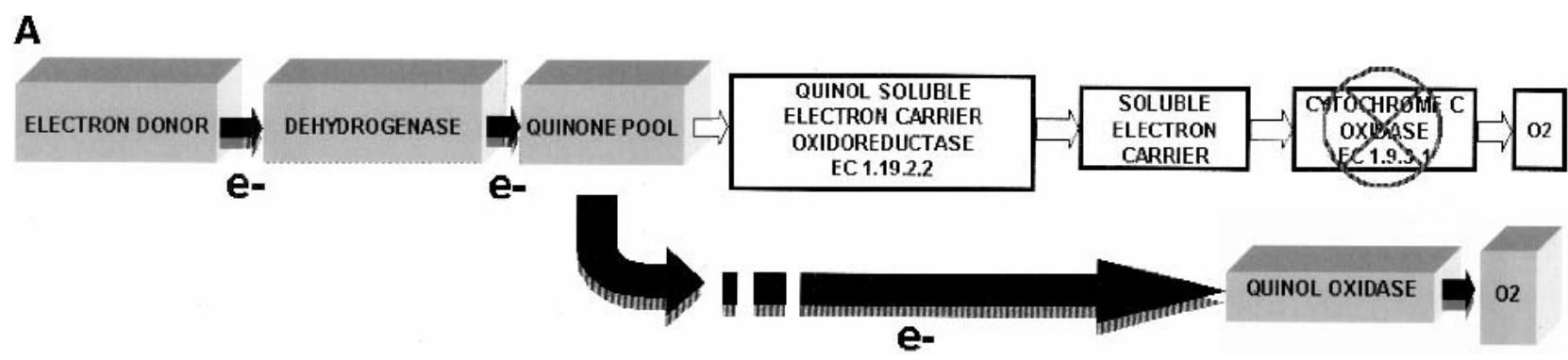

B

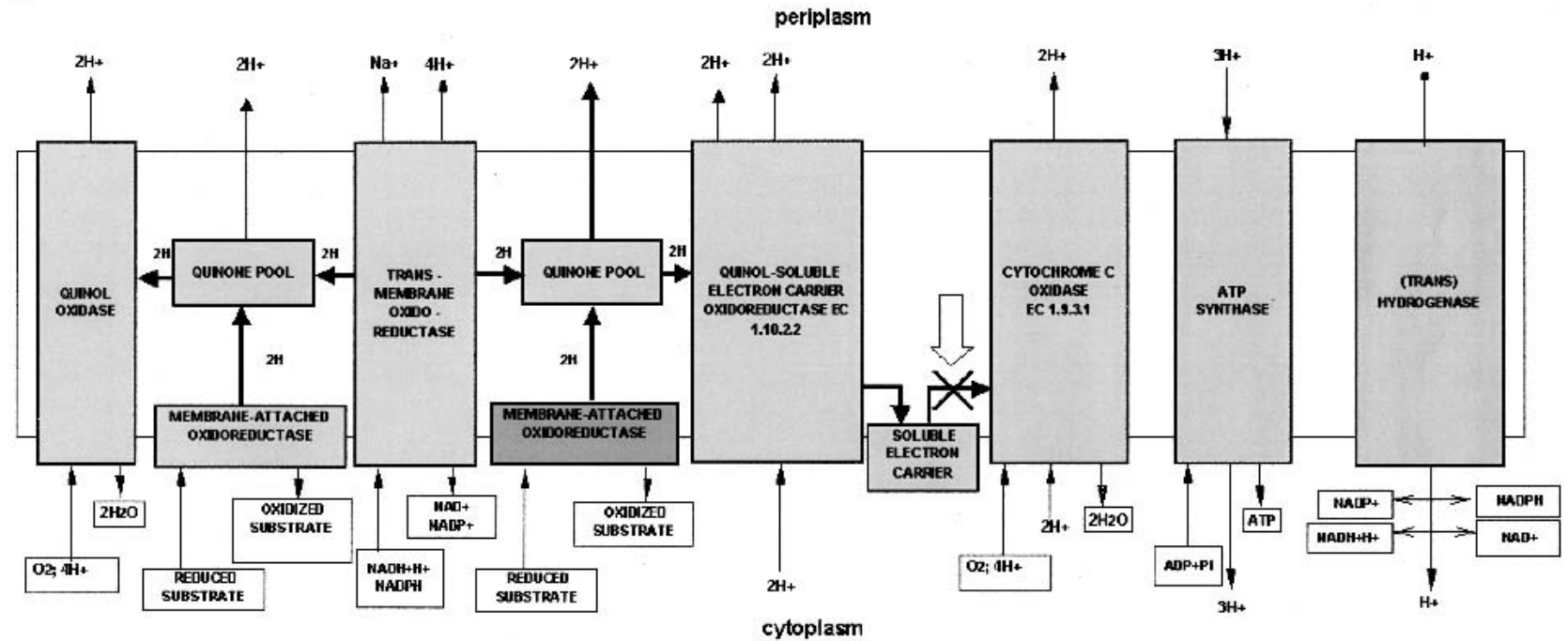

C

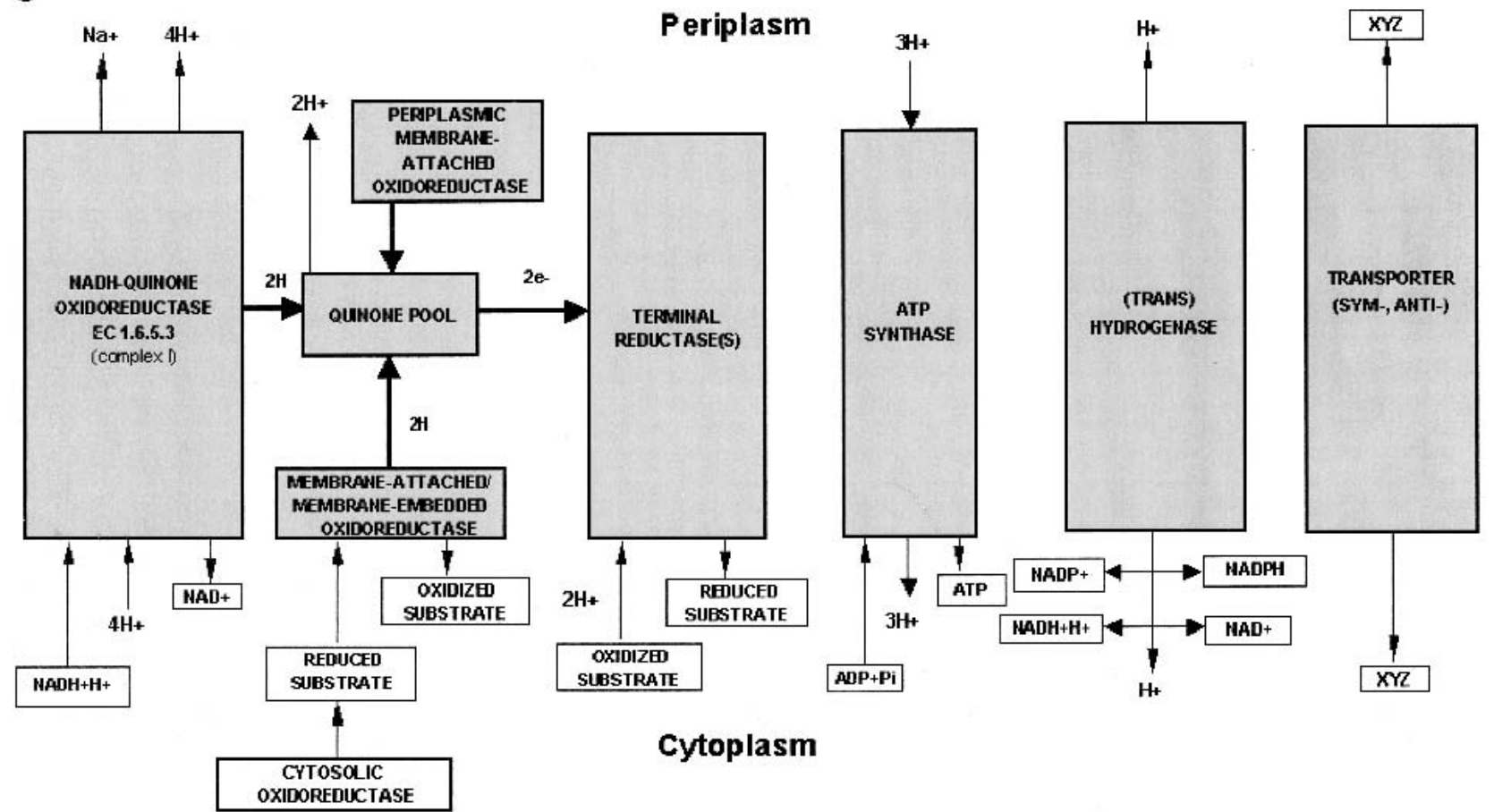

Figure 3 Graphical visualization of the functional reconstruction of Xylella fastidiosa aerobic and anaerobic respiration. (A) Diagrammatic representation of aerobic respiration. Three-dimensional boxes show the presence of functional components and filled arrows indicate electron flow. (B) Detailed spatial disposition of membrane components of aerobic respiratory chain. The absence of cytochrome $c$ oxidase is designated by the cross and arrow. (C) Overview of the anaerobic respiratory chain. Reconstructions show proton translocation and oxidative phosphorylation. 
b and cytochrome c1 precursor [RXFA00908-910], respectively). Thus, we can suggest that, because the cytochrome $o$ (bo) ubiquinone oxidase is the only available terminal oxidase, it provides a strong potential control point and drug target for these phytopathogens. Although soluble periplasmic cytochrome c has not been found in the $X f$ genomes, another protein, the copper-containing protein azurin (RXFA00507), could perform electron transport in the periplasm between ubiquinol-cytochrome $\mathrm{c}$ reductase and the missing cytochrome c oxidase.

Anaerobic respiration in $X f$ is also quite limited (Fig. 3C). The entire system for nitrate utilization to dinitrogen is absent. Additionally, the enzymes converting nitrate into ammonia appear to be absent. $X f$ clearly prefers anaerobic respiration based on sulfur metabolism. The entire operon that encodes enzymes for the use and reduction of sulfate to sulfide is present (sulfate adenylyltransferase [EC 2.7.7.4; RXFA01500-1501], adenylylsulfate kinase [EC2.7.1.25; RXFA01501], phosphoadenosine phosphosulfate reductase [EC 1.8.99.4; RXFA01497], and sulfite reductase [EC 1.8.1.2; RXFA01498-1499]). Indication that another type of anaerobic respiration may be present is suggested by the presence of arsenate reductase (RXFA00115). The simplicity and the type of anaerobic respiratory complex indicate that the enzymes of the sulfate-sulfide reduction pathway could also serve as a potential drug target.

$X f$ has a well-defined operon encoding $\mathrm{H}^{+}$-transporting ATP synthase (EC 3.6.1.34; RXFA01142-1149). There is no indication of any other type of ATP synthase. Proton balance seems to be maintained mainly by NADH-quinone oxidoreductase (EC 1.6.5.3; RXFA00305-318), cytochrome o ubiquinol oxidase, quinone pool, and ubiquinol-cytochrome c reductase that pump protons out and the reverse catalyzed by the $\mathrm{H}^{+}$-transporting ATP synthase.

$X$. fastidiosa is able to use very few sugars (glucose, fructose, mannose, ribose, glycerol, $\mathrm{N}$-acetylglucosamine) and cellulose. Paradoxically, despite its ability to use these sugars, it was not apparent from previous studies (Simpson et al. 2000) how these sugars are transported into the cell. We have identified candidates for some of the sugar transport systems, which have orthologs in Xfpv almond and Xfpv oleander. For example, based on the chromosomal neighborhood of the XFA ORF, RXFA01462, which is positioned at the beginning of a N-acetylglucosamine utilization operon, this ORF is likely to be the $\mathrm{N}$-acetylglucosamine and glucosamine transporter. The Xylella genomes contain one family $1 \mathrm{ABC}$ transporter, the subunits of which are dispersed throughout the genome. The sugar transport permease (RXFA02446, RXFA02467) and the periplasmic binding protein (RXFA02448) are found adjacent to an enzyme involved in glucose metabolism. The ATPase subunit (RXFA01067) is found in a distant region of the genome. We propose that this sugar transporter is likely to be involved in glucose uptake.

The range of amino acids that might be used by Xylella as a sole carbon source seems to be limited to D- and L-alanine (via alanine racemase and D-amino acid dehydrogenase), glycine (via glycine cleavage system) and L-glutamate (via glutamate dehydrogenase). Thus, some carbon and energy source, other than amino acids and an oligopeptide mixture, should be provided for efficient growth of Xylella. This carbon source might be glycerol (all genes for glycerol utilization were found, including glycerol uptake protein, glycerol kinase, and glycerol-3-phosphate dehydrogenases), malate or oxaloacetate (C4-dicarboxylate transporter and NADP-dependent ma- lic enzyme are clustered together), glucose, fructose, or Nacetylglucosamine. Most likely, an optimal growth medium for $X f$ would be predicted to contain glycerol as a carbon and energy source and L-glutamate as both a nitrogen and carbon source. In addition, the clear preference of $X f$ for sulfate reduction-based anaerobic respiration could indicate that the best medium for the $X f$ family would contain an increased concentration of sulfur-containing compounds.

\section{Growth Medium}

Culture media for $X f$ were first developed for both grape and almond strains (Davis et al. 1978) and eventually for other $X$. fastidiosa strains such as those from peach and periwinkle (Davis et al. 1981a). Determination of the minimum metabolic requirements for this organism would thus allow improvement in medium composition for optimal growth and make this organism more tractable for study. Based on our functional reconstruction of the sequenced $X f$ genomes, we generated predictions of the nutritional profile of these phytopathogens, and we designed growth experiments to test and develop a defined medium. A commonly used growth medium was modified by adding one or more of the predicted compounds. The standard growth medium used was PW (Davis et al. 1981b). Medium components that were changed included those that are putative sources for carbon, nitrogen, and iron. The bacterial strain used for the experiments was $X f$ pv almond (Dixon). Numbers of colony-forming units (CFU) of $X f$ were determined after 7 days growth at $28^{\circ} \mathrm{C}$.

We compared the growth of $X f p v$ almond on standard $\mathrm{PW}$ as the growth medium $\left(1.13 \times 10^{9} \mathrm{CFU} \mathrm{m}{ }^{-1}\right)$, and determined that the addition of fructose $\left(8.40 \times 10^{8} \mathrm{CFU} \mathrm{ml}{ }^{-1}\right)$, oxaloacetate $\left(5.80 \times 10^{8} \mathrm{CFU} \mathrm{ml}^{-1}\right), \mathrm{N}$-acetylglucosamine $\left(2.90 \times 10^{8} \mathrm{CFU} \mathrm{ml}^{-1}\right)$, or $\alpha$-keto-glutarate $\left(7.00 \times 10^{8} \mathrm{CFU}\right.$ $\mathrm{ml}^{-1}$ ) could substitute for the Bovine serum albumin (BSA) constituent of the PW medium when added separately. In comparison, glycerol $\left(2.93 \times 10^{7} \mathrm{CFU} \mathrm{ml}{ }^{-1}\right)$ and glucose $(5.70$ $\times 10^{6} \mathrm{CFU} \mathrm{ml}{ }^{-1}$ ) could not substitute as well for BSA in the PW-based medium. Sucrose did not substitute for BSA, as was mentioned in previous studies (Davis et al. 1981b). The different iron sources used were hemin chloride $\left(1.13 \times 10^{9} \mathrm{CFU}\right.$ $\left.\mathrm{ml}^{-1}\right)$, ferric pyrophosphate $\left(4.60 \times 10^{8} \mathrm{CFU} \mathrm{ml}{ }^{-1}\right)$, or iron sulfate $\left(3.10 \times 10^{8} \mathrm{CFU} \mathrm{ml}^{-1}\right)$. These iron sources affected the growth of $X f$ similarly. The addition of the amino acids glycine $\left(4.40 \times 10^{8}\right.$ and $\left.2.9 \times 10^{8} \mathrm{CFU} \mathrm{m} \mathrm{m}^{-1}\right)$ or glycine plus L-alanine $\left(9.50 \times 10^{8}\right.$ and $\left.6.83 \times 10^{8} \mathrm{CFU} \mathrm{m}^{-1}\right)$ to the PW base did not appreciably improve growth, although Xylella approached the growth properties with the PW-based medium. Indeed, when glycine was omitted from the modified medium, less growth was observed (data not shown). Xylella appear to grow better in the presence of glycine, although the exact reason for this is unclear. When L-cysteine was added to PW, no growth was observed. Our results indicate that when BSA is removed from the PW-based medium, the best growth conditions are provided by the addition of fructose, glutamine, glycine, and iron sulfate. Thus, $X f$ was found to grow well on media components predicted by the metabolic reconstruction when they were added as substitutes for BSA in the basal medium.

The aspects of the genome comparisons and functional reconstructions presented here represent the relative highlights of the biological analysis discerned from the genome analysis of the phytopathogenic $X$. fastidiosa $(X f)$ species. A more complete description of the genome analyses and recon- 
structions are presented elsewhere (Bhattacharyya et al., in press). However, there are two intriguing questions posed from this study. First, does the unique phage insertion sequence in the $X f$ citrus strain indeed bear potential hostspecific functions? Second, can the strong potential control point identified in the aerobic respiratory chain provide a potential drug target in these phytopathogens? We envision that microarray, genetic, proteomic, and pharmacological approaches will provide the tools to address these new challenges identified from this in silico analysis of the genome sequences of these organisms.

\section{METHODS}

\section{Sequencing and Assembly}

Genomic DNA for strains of both $X f p v$ almond (Dixon) and oleander (Ann-1) were obtained from the collection of isolates from A.H.P, at the University of California, Berkeley. Using a whole genome shotgun approach, purified DNA was fragmented using a GeneMachines Hydroshear, end repaired and size fractionated on agarose gels. Fragments in the 3- to 4-kb size range were excised, eluted, and blunt-end ligated to SmaIlinearized pUC18 DNA. DNA from overnight cultures (180 $\mu \mathrm{L}$ ) of these libraries was purified using an automated 96-well SPRI protocol (Hawkins et al. 1994). These templates were cycle-sequenced using both universal M13-forward and M13reverse primers with dye-terminator chemistry (AP Biotech). The resulting products were sequenced on MegaBACE 1000 capillary sequencers. Raw traces were preprocessed using Cimarron software version 2.1905 (AP Biotech) and basecalled using Phred (Ewing et al. 1998). Read lengths in libraries typically averaged $500-550$ bases with Phred $\geq 20$. Individual sequence reads were assembled using Phrap (http:// bozeman.mbt.washington.edu/phrap.docs/phrap.html), and contig order/orientation was established by using technology developed at the Joint Genome Institute (JGI) (e.g., readsincontig, phrap2gapspan) in conjunction with the graphical sequence editor, Consed (Gordon et al. 1998). Libraries were sequenced to at least $8 \times$ depth of coverage. The DNA sequences of the two Xylella strains (almond and oleander strains) are available at the JGI Web server (http:// www.jgi.doe.gov/JGI_microbial/html/).

\section{ORF Prediction}

ORFs were predicted with a proprietary ORF-calling software system developed at Integrated Genomics. The system automatically combines its own statistically predicted ORFs with ORFs derived from external sources (if available) and BLAST and FASTA similarities. ORFs were predicted using this approach for all three $X f$ genomes including the previously published Xf pv citrus (Simpson et al. 2000) whose DNA sequence was extracted from GenBank. The ORF prediction tools were not run on contigs with Phred $<20$ reads.

\section{Genome Analysis: Annotations, Functional Reconstructions, and Comparative Genomics}

We used the ERGO bioinformatics suite (http://www. integratedgenomics.com) (Kyrpides et al. 2000; Selkov et al. 2000; DelVecchio et al. 2002; Kapatral et al. 2002). ERGO contains an integration of over 450 genomes (including complete and partial, public, and proprietary from all kingdoms), with an extensive manually curated set of functional annotations and over 5000 manually curated cellular pathways, which is part of the Integrated Genomics proprietary Pathway Database. The analysis of the three $X f$ strains was performed as previously described (Kyrpides et al. 2000; Selkov et al. 2000; DelVecchio et al. 2002; Kapatral et al. 2002). The gene clustering based on sequence (i.e., ortholog and paralog clus- ters), as well as the one based on chromosomal context (i.e., chromosomal and fusion clusters), were computed on the basis of proprietary technology developed at Integrated Genomics. Comparative genomics technology such as GenomeWalk (available through ERGO suite) was also used. GenomeWalk provides a graphical whole genome comparison environment that facilitates the identification of unique chromosomal regions between closely related genomes. Workbench allows the identification of the common and unique clusters of genes between genomes, by using clustering algorithms to calculate protein clusters between a set of organisms.

\section{ACKNOWLEDGMENTS}

We thank members of the bioinformatics and genome analysis group at Integrated Genomics, specifically, Gordon Pusch, Lynn Jablonski, Olga Vassieva, Allen Bartman, and Warren Gardner for assistance during preliminary stages of the genome analysis. We would also like to thank Ken Frankel (JGI) for his contribution in the genomic sequence analysis. Funding for this work was supported by the Integrated Genomics research and development program, and by the U.S. Department of Energy research grants, from the Office of Biological and Environmental Research, by the University of California, Lawrence Livermore National Laboratory under Contract No. W-7405-Eng-48, Lawrence Berkeley National Laboratory under contract No. DE-AC03 76SF00098, and Los Alamos National Laboratory under contract No. W-7405-ENG-36.

The publication costs of this article were defrayed in part by payment of page charges. This article must therefore be hereby marked "advertisement" in accordance with 18 USC section 1734 solely to indicate this fact.

\section{REFERENCES}

Bhattacharyya, A., Stilwagen, S., Ivanova, N., D'Souza, M., Bernal, A., Lykidis, A., Kapatral, V., Anderson, I., Larsen, N., Los, T., et al. 2002. Proc. Natl. Acad. Sci., in press.

Davis, M.J. and Thompson, S.V. 1980. Etiological role of a xylem-limited bacterium causing Pierce's disease in almond leaf scorch. Phytopathology 70: 472-475.

Davis, M.J., Purcell, A.H., and Thompson, S.V. 1978. Pierce's disease of grapevines: Isolation of the causal bacterium. Science 199: 75-77.

Davis, M.J., Whitcomb, R.F., and Gillespie Jr., A.G. 1981a. Fastidious bacteria of plant vascular tissue and invertebrates (including so called rickettsia-like bacteria). In The prokaryotes: A handbook on habits, isolation, and identification of bacteria. (eds. M.P. Starr, H. Stolp, H.G. Truper, A. Balows, and H.G. Schlegel), pp. 2172-2188. Springer-Verlag, Heidelberg.

Davis, M.J., French, W.J., and Schaad, N.W. 1981b. Axenic culture of the bacteria associated with phony disease of peach and plum leaf scald. Curr. Microbiol. 6: 309-314.

DelVecchio, V.G., Kapatral, V., Redkar, R.J., Patra, G., Mujer, C., Los, T., Ivanova, N., Anderson, I., Bhattacharyya, A., Lykidis, A.,et al. 2002. The genome sequence of the facultative intracellular pathogen Brucella melitensis. Proc. Natl. Acad. Sci. 99: 443-448.

Ewing, B., Hillier, L., Wendl, M.C., and Green, P. 1998. Base-calling of automated sequencer traces using phred. I. Accuracy assessment. Genome Res. 8: 175-185.

Fleischmann, R.D., Adams, M.D., White, O., Clayton, R.A., Kirkness, E.F., Kerlavage, A.R., Bult, C.J., Tomb, J.F., Dougherty, B.A., Merrick, J.M., et al. 1995. Whole-genome random sequencing and assembly of Haemophilus influenzae Rd. Science 269: 496-512.

Forterre, P. 1999. Displacement of cellular proteins by functional analogues from plasmids or viruses could explain puzzling phylogenies of many DNA informational proteins. Mol. Microbiol. 33: $457-465$

Galperin, M.Y. and Koonin, E.V. 1999. Functional genomics and enzyme evolution. Homologous and analogous enzymes encoded in microbial genomes. Genetica 106: 159-170.

Gordon, D., Abajian, C., and Green, P. 1998. Consed: A graphical tool for sequence finishing. Genome Res. 8: 195-202.

Hawkins, T.L., O'Connor-Morin, T., Roy, A., and Santillan, C. 1994. DNA purification and isolation using a solid-phase. Nucleic Acids Res. 22: 4543-4544. 
Hendson, M., Purcell, A.H., Chen, D., Smart, C., Guilhabert, M., and Kirkpatrick, B. 2001. Genetic diversity of Pierce's disease strains and other pathotypes of Xylella fastidiosa. Appl. Environ. Microbiol. 67: 895-903.

Kapatral, V., Anderson, I., Ivanova, N., Reznik, G., Los, T., Lykidis, A., Bhattacharyya, A., Bartman, A., Gardner, W., Grechkin, G., et al. 2002. Genome sequence and analysis of the oral bacterium Fusobacterium nucleatum strain ATCC 25586. J. Bacteriol. 184: $2005-2018$.

Kyrpides, N.C., Ouzounis, C.A., Iliopoulos, I., Vonstein, V., and Overbeek, R. 2000. Analysis of the Thermotoga maritima genome combining a variety of sequence similarity and genome context tools. Nucleic Acids Res. 28: 4573-4576.

Mircetich, S.M., Lowe, S.K., Moller, J.W., and Nyland, G. 1976. Etiology of almond leaf scorch disease and transmission of the causal agent. Phytopathology 66: 17-24

Moller, W.J., Sanborn, R.R., Mircetich, S.M., Williams, H.E., and Beutel, J.A. 1974. A newly recognized leaf scorch disease of almond. Plant Dis. Rep. 58: 99-101.

Parkhill, J. 2000. In defense of complete genomes. Nature 18: $493-494$.

Purcell, A.H. 1997. Xylella fastidiosa, a regional problem or global threat? Journal of Plant Pathology 79: 99-105.

Purcell, A.H., Saunders, S.R., Hendson, M., Grebus, M.E., and Henry, M.J. 1999. Causal role of Xylella fastidiosa in oleander leaf scorch disease. Phytopathology 89: 53-58.
Rohwer, F. and Edwards, R. 2002. The phage proteomic tree: A genome-based taxonomy for phage. J. Bacteriol. 184: 4529-4535.

Selkov, E., Overbeek, R., Kogan, Y., Chu, L., Vonstein, V., Holmes, D., Silver, S., Haselkorn, R., and Fonstein, M. 2000. Functional analysis of gapped microbial genomes: Amino acid metabolism of Thiobacillus ferrooxidans. Proc. Natl. Acad. Sci. 97: 3509-3514.

Simpson, A.J., Reinach, F.C., Arruda, P., Abreu, F.A., Acencio, M., Alvarenga, R., Alves, I.M., Araya, J.E., Baia, G.S., Baptista, C.S., et al. 2000. The genome sequence of the plant pathogen Xylella fastidiosa. Nature 406: 151-157.

Wells, J.M., Raju, B.C., Hung, H.Y., Weisberg, W.G., Mandelco-Paul, L., and Brenner, D.J. 1987. Xylella fastidiosa new-genus new-species gram-negative xylem-limited fastidious plant bacteria related to Xanthomonas spp. Int. J. Syst. Bacteriol. 37: $136-143$

\section{WEB SITE REFERENCES}

http://www.jgi.doe.gov/JGI_microbial/html/index.html; JGI Web server.

http://www.integratedgenomics.com; ERGO bioinformatics suite

Received April 19, 2002; accepted in revised form July 30, 2002. 


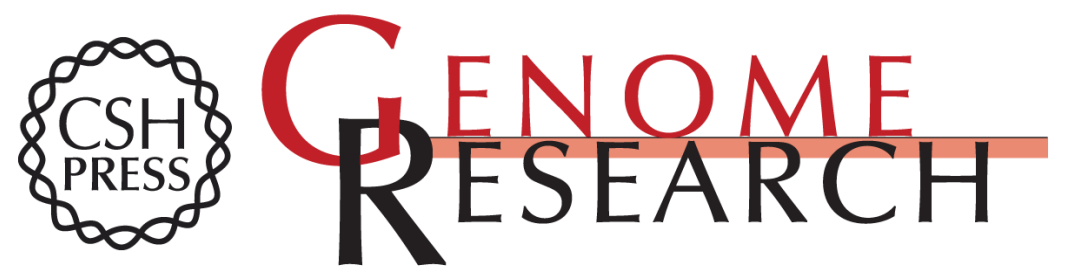

\section{Draft Sequencing and Comparative Genomics of Xylella fastidiosa Strains Reveal Novel Biological Insights}

Anamitra Bhattacharyya, Stephanie Stilwagen, Gary Reznik, et al.

Genome Res. 2002 12: 1556-1563

Access the most recent version at doi:10.1101/gr.370702

References This article cites 22 articles, 9 of which can be accessed free at:

http://genome.cshlp.org/content/12/10/1556.full.html\#ref-list-1

\section{License}

Email Alerting Receive free email alerts when new articles cite this article - sign up in the box at the Service top right corner of the article or click here.

\section{Affordable, Accurate Sequencing.}

